\title{
Natural killer and natural killer T-like cells in splenectomised patients
}

\author{
EWELINA GRYWALSKA ${ }^{l}$, JUSTYNA MARKOWICZ ${ }^{l}$, DOROTA SIWICKA ${ }^{l}$, MARCIN PASIARSKI $^{2}$, \\ AGATA SURDACKA ${ }^{l}$, AGNIESZKA GRAFKA ${ }^{l}$, AGNIESZKA MALEC ${ }^{3}$, MATEUSZ BILSKI', \\ TOMASZ ROMAN ${ }^{\prime}, J A C E K$ ROLIŃSKI
}

${ }^{1}$ Department of Clinical Immunology and Immunotherapy, Medical University of Lublin, Lublin, Poland ${ }^{2}$ Department of Hematology, Holycross Cancer Center, Kielce, Poland

${ }^{3}$ Department of Obstetrics and Gynecology, Medical University of Lublin, Lublin, Poland

\begin{abstract}
Introduction: Natural killer cells (NK cells) present a unique ability to recognize and kill cells infected with a variety of pathogens, regardless of prior immunization. Natural killer T-like cells (NKT-like cells) are increased in clinical conditions associated with chronic activation of the immune system. Splenectomised patients are susceptible to infections, especially those caused by encapsulated bacteria. While the knowledge about humoral immunity disturbances in asplenic persons is well established, the abnormalities of cellular response remain still under investigation.

Aim of the study was to estimate the impact of splenectomy on postoperative quantitative changes of NK cells (CD3-/CD16+CD56+) and NKT-like cells $(C D 3+/ C D 16+C D 56+)$ as two important lymphocyte subsets involved in host defence against various pathogens.

Material and methods: Assessment of NK and NKT-like cells was performed by the flow cytometry in a group of 100 splenectomised patients and 20 healthy volunteers.

Results: Patients with secondary asplenia displayed a decreased ratio of NK cells (CD3-/ $C D 16+C D 56+)(p=0.012)$ and a higher ratio of NKT-like cells $(C D 3+/ C D 16+C D 56+)(p=0.001)$ in comparison to controls. Patients who underwent elective splenectomy presented a higher amount of $N K$ cells $(C D 3-/ C D 16+C D 56+)$ than those with post-traumatic spleen removal $(p=0.035)$. The time since surgery negatively correlated with $\mathrm{NK}$ cells counts $(C D 3-/ C D 16+C D 56+)$. In those patients who noticed increased susceptibility to infections, NK cells number (CD3-/CD16+CD56+) was lower ( $p=$ $=0.007)$ than in those patients who did not observe any change in prevalence of infections. Moreover, those patients who noticed an increased infection rate had higher frequencies of NKT-like cells (CD3-/ $C D 16+C D 56+)$ comparing to those who did not observe any change in the prevalence of infections $(p=0.006)$.

Conclusions: This study provides a further piece of information on the complex immune disturbances in splenectomised individuals leading to the increased risk of bacterial infections. Results obtained suggest that monitoring of NK and NKT-like cells number may provide useful information for determining asplenia-related immunosuppression.
\end{abstract}

Key words: splenectomy, NK cells, NKT-like cells, immunity, infections.

(Centr Eur J Immunol 2013; 38 (3): 372-379)

\section{Introduction}

Spleen is the largest lymphatic organ in the human body. Functionally it plays a fundamental role in bacterial clearance either by antibody response or macrophage bacterici- dal capacity [1, 2]. Spleen is critical in clearing opsonised encapsulated bacteria such as pneumococci, meningococci, Haemophilus influenzae and Escherichia coli [3]. Its specific role is related to marginal zone macrophages, which are able to detect and capture encapsulated bacteria, and

Correspondence: Dorota Siwicka, Department of Clinical Immunology and Immunotherapy, Medical University of Lublin, Chodzki 4a, 20-093 Lublin, Poland, tel. +48 600067 955, e-mail: dsiw@wp.pl 
marginal zone B cells, which respond to capsule polysaccharide antigens by differentiating into IgM-producing memory B cells or antigen presenting cells [4]. The spleen is crucial in regulating immune homoeostasis. It combines both innate and adaptive immunity [5]. After splenectomy, mechanisms that play a fundamental role in bacterial clearance are impaired, what results in an increased risk of lifethreatening infections $[6,7]$. Due to the high risk of fulminant infections occurring in this group, it is essential to take preventive actions [8].

Natural killer (NK) cells are defined as large granular lymphocytes (LGL) with CD3-/CD16+CD56+ phenotype [9], and constitute approximately $4-15 \%$ of blood lymphocytes [10]. Natural killer cells are not a homogeneous cell population. In humans, they can be divided into two major subtypes: CD56 bright and CD56 ${ }^{\mathrm{dim}}$, based on the expression of the surface markers (CD16 and CD56) [11-13]. The unique ability of NK lymphocytes to recognize and kill cells infected with a variety of pathogens, regardless of prior immunization, make them first-line host defence against viruses or other intracellular pathogens [14]. They also participate in tumour immunosurveillance $[15,16]$ and autoimmunity [17]. It was recently discovered that NK cells have also the capacity for memory-like immune response [18]. Natural killer cells are able to mediate direct cytotoxicity and antibody-dependent cellular cytotoxicity (ADCC) against infected or neoplastic cells [19]. They act through exocytosis of various proteins including perforin, granzymes [20], FasL [21] which mediate target-cell killing and production of IFN- $\gamma$ and other immunoregulatory cytokines [22]. By production of cytokines and chemokines, NK cells regulate the functions of other immune cells, such as dendritic cells (DCs) [23], neutrophils [24], macrophages and monocytes [25]. Moreover NK cell-derived cytokines activate innate immune responses and subsequently influence the development of adaptive immune response [26-28]. The adverse effects of uncontrolled or inappropriate NK cell responses result in different pathological conditions such as allograft rejection and various autoimmune diseases [29]. Complete NK-cell deficiencies in humans result in overwhelming fatal infections in childhood [30].

Natural killer T (NKT) cells represent a small but distinctive population of $\mathrm{T}$ lymphocytes which constitute approximately $0.02-0.2 \%$ of circulating $\mathrm{T}$ cells in humans [31]. Natural killer T cells are prevalent in the liver (about $4 \%$ of human hepatic T cells,) bone marrow and thymus [32]. They display properties of both T cells and NK cells through expression of an invariant $\alpha \beta$ T-cell receptor (TCR) (V $\alpha 14 / \mathrm{J} \alpha 281$ in mice and $\mathrm{V} \alpha 24 / \mathrm{J} \alpha \mathrm{Q}$ in humans), and NK cells surface marker NK1.1 (CD161) [33, 34]. Natural killer T-like cells can share other features with NK cells as well, e.g. expression of cytotoxic molecules [35]. In contrast to conventional T-lymphocytes, NKT cells do not respond to antigens presented by a classical major histocompatibility complex (MHC) but recognize a wide range of glycolipid antigens presented by the MHC I-like molecule CD1d [36]. The best known example of such antigen is $\alpha$-galactosylceramide ( $\alpha$-GalCer) [37]. Activation via CD1d initiates rapid production of a large number of both Th1 and Th2 immunoregulatory cytokines including IL-4, IL-10 and IFN- $\gamma$, activation of several immune cells (NK cells, T, B lymphocytes, dendritic cells) and increase in the cytolytic activity of NKT cells [38]. Due to the above abilities, NKT cells are called a "bridge" between innate and adaptive immunity [39]. Natural killer T cells are involved in a variety of immunological processes. They induce a host immune response against infectious pathogens, promote tumour immunosurveillance or immunosuppression and play a regulatory role in autoimmunity and allergic diseases [37, 4045]. Natural killer T cells do not represent a homogeneous population. Three types of NKT cells have been described [46, 47].

CD1d-restricted NKT cells are important for host defence against various microbial pathogens. They contribute bacterial clearance through two different pathways. Direct recognition of bacterial lipids may occur via TCR [48]. In absence of microbial glycolipids, NKT cells are stimulated by IL-12, produced by dendritic cells and macrophages previously activated by pathogens [49]. Natural killer $\mathrm{T}$ cells activation may be responsible for septic shock reaction [50]. Furthermore, NKT cell subpopulations might play opposite roles due to functional differences. Type I and type II NKT cells display cross-regulation abilities, forming a new immunoregulatory axis $[42,51]$.

Splenectomy severely affects immunity. While the knowledge about humoral immunity disturbances in splenectomised individuals is well established, the abnormalities of cellular response remain still under investigation. The main aim of the present study was to estimate the impact of splenectomy on postoperative quantitative changes of NK and NKT-like cells as two important lymphocyte subsets involved in host defence against various pathogens.

\section{Material and methods}

\section{Patients and controls}

A study group of 100 subjects (51 women and 49 men), with an average age of $34.28 \pm 22.87$ years (median: 36 , min. 18, max. 69 years), was recruited at the Department of Clinical Immunology and Immunotherapy of the Medical University of Lublin between October 2010 and December 2012. Fifty-six patients (56\%) were splenectomised because of a blunt abdominal trauma with spleen injury. In 28 persons (28\%), the reason of splenectomy was hereditary spherocytosis and 16 patients $(16 \%)$ had had immune thrombocytopenic purpura (ITP). The average time since the splenectomy was $8.83 \pm 9.72$ years. Seventy-four persons $(74 \%)$ reported more frequent infections after 
splenectomy and 26 patients (26\%) did not observe any change in prevalence of upper respiratory tract infections.

Control samples of peripheral blood (PB) were obtained from 20 healthy volunteers ( 8 women and 12 men) aged from 19 to 73 years (median age: 40.5 years, mean: 44.82 \pm 31.12 years). Nobody of the splenectomised subjects in the study group and controls complained of ailments characteristic of the current infection. None of them was taking immunosuppressive or immunomodulative treatment within the last 12 months. The Local Ethical Committee at the Medical University of Lublin approved the research and patients gave their prior written consent.

\section{Assessment of NK (CD3-/CD16+CD56+) and NKT-like (CD3+/CD16+CD56+) cells}

Peripheral blood in an amount of $1 \mathrm{ml}$ was taken to tubes with an EDTA anticoagulant. Percentages of NK and NKT-like cells were evaluated with flow cytometry using monoclonal antibodies (MoAbs) anti-CD3 FITC/CD16+ CD56 PE/CD45 PerCP (BD Biosciences), which allowed for simultaneous assessment of $\mathrm{T}(\mathrm{CD} 3+)$ lymphocytes and NK (CD16+CD56+) cells. During analysis, the CD3+/ CD16+CD56+ population was also determined. A standard, whole-blood assay with erythrocyte cell lysis was used to prepare the PB samples. The percentage of positive cells was measured from a cut-off set using isotype matched nonspecific control antibody. Three-colour immunofluorescence analyses were performed using a FACS Calibur flow cytometer (Becton Dickinson) equipped with $488 \mathrm{~nm}$ argon laser. A minimum of 10000 events was acquired and analyzed using CellQuest Software. The percentage and absolute counts of cells expressing surface markers were analyzed. Dot plots, illustrating the analysis method for the

A

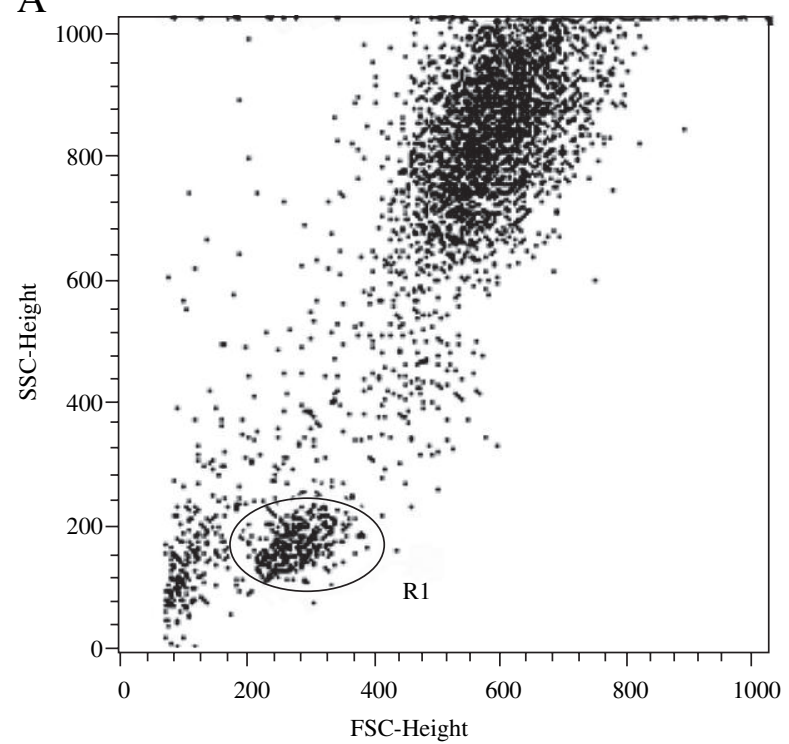

identification of NK and NKT-like cells are shown in Figure 1.

\section{Statistical analysis}

Differences between two groups were assessed using the Mann-Whitney $U$ test. Spearman rank test was used to assess correlations between the variables. Statistica 9.0 PL software was used for all statistical procedures. Differences were considered as statistically significant when the $p$ value was less than 0.05 .

\section{Results}

The immunophenotypic analysis revealed differences between the study and control groups in total lymphocytes as well as particular numbers of lymphocyte subsets. The total lymphocyte count, percentages and absolute counts of T lymphocytes, NK cells and NKT-like cells in the study and control groups are presented in Table 1.

Patients with lymphocyte levels in the normal range $\left[1.5-4 \times 10^{3} / \mathrm{mm}^{3}\right]$ represented $84 \%$ of the study group, lymphocytosis occurred in $10 \%$ of cases, lymphocytopenia in $6 \%$ of cases. The T lymphocytes (CD3+) level as compared to the normal range [60-75\%] was elevated in $23 \%$ of individuals after splenectomy and normal in $67 \%$ of cases. In both groups, the level of NK cells (CD3-/CD16+CD56+) exceeded the level of NKT-like cells (CD3+/CD16+ CD56+). Splenectomised patients had a lower amount of NK cells (CD3-/CD16+CD56+) and a higher amount of NKT-like cells (CD3+/CD16+CD56+). Spleen removal was followed by changes in the ratio of NK and NKT-like cell subsets. Patients with secondary asplenia displayed a decreased ratio of $\mathrm{NK}$ cells (CD3-/CD16+CD56+)

B

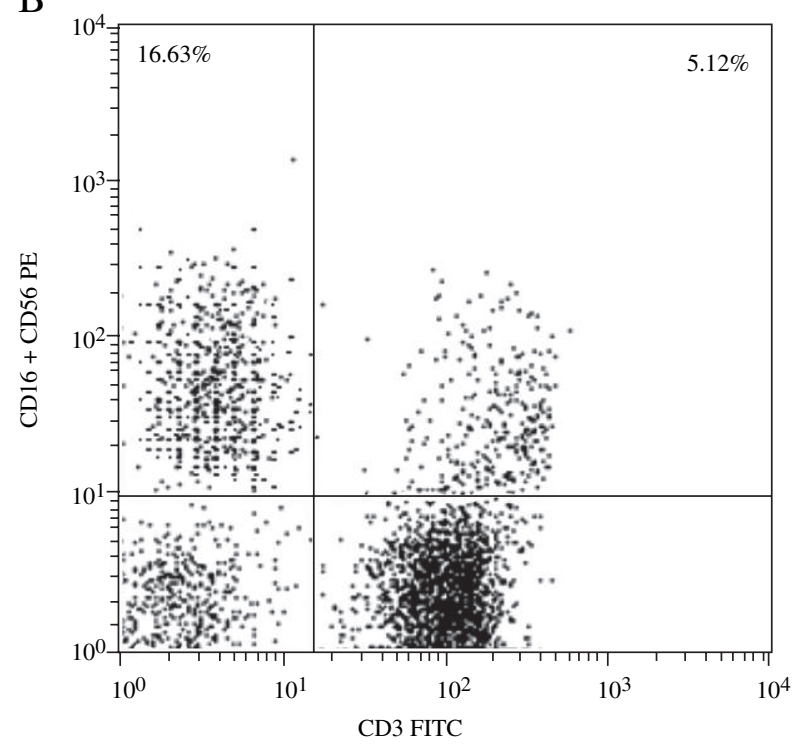

Fig. 1. Dot-plots showing the analysis method for the identification of NK and NKT-like cells in a splenectomised patient 
Table 1. Total lymphocyte count, percentages and absolute counts of T lymphocytes, NK cells and NKT-like cells in the study and control groups

\begin{tabular}{lcc}
\hline & $\begin{array}{c}\text { Study group } \\
(\boldsymbol{n}=\mathbf{1 0 0})\end{array}$ & $\begin{array}{c}\text { Control group } \\
(\boldsymbol{n}=\mathbf{2 0})\end{array}$ \\
\hline Total lymphocytes count $\left[10^{3} / \mathrm{mm}^{3}\right]$ & $2.66 \pm 0.87$ & $2.45 \pm 0.6$ \\
\hline T lymphocytes (CD3+) $[\%]$ & $65.98 \pm 8.14$ & $65.75 \pm 13.25$ \\
\hline $\begin{array}{l}\text { T lymphocytes (CD3+) } \\
{\left[10^{3} / \mathrm{mm}^{3}\right]}\end{array}$ & $1.74 \pm 0.59$ & $1.61 \pm 0.52$ \\
\hline $\begin{array}{l}\text { NK cells (CD3-/CD16+CD56+) } \\
{[\%]}\end{array}$ & $15.68 \pm 8.03$ & $20.23 \pm 10.35$ \\
\hline $\begin{array}{l}\text { NK cells }(\mathrm{CD} 3-/ C D 16+C D 56+) \\
{\left[10^{3} / \mathrm{mm}^{3}\right]}\end{array}$ & $0.42 \pm 0.27$ & $0.5 \pm 0.3$ \\
\hline $\begin{array}{l}\text { NKT-like cells } \\
(\mathrm{CD} 3+/ \mathrm{CD} 16+\mathrm{CD} 56+)[\%]\end{array}$ & $4.42 \pm 3.08$ & $2.09 \pm 1.03$ \\
\hline $\begin{array}{l}\text { NKT-like cells } \\
(\mathrm{CD} 3+/ \mathrm{CD} 16+\mathrm{CD} 56+)\left[10^{3} / \mathrm{mm}^{3}\right]\end{array}$ & $0.12 \pm 0.12$ & $0.05 \pm 0.03$ \\
\hline
\end{tabular}

$(p=0.012)$ and a higher ratio of NKT-like cells $(\mathrm{CD} 3+/ \mathrm{CD} 16+\mathrm{CD} 56+)(p=0.001)$ in comparison to controls (Table 1).

We revealed a positive correlation between $\mathrm{T}$ lymphocytes (CD3+) and NK cells (CD3-/CD16+CD56+), as well as NKT-like cells (CD3+/CD16+CD56+) number $(r=0.426, p<0.0001$, and $r=0.414, p<0.0001$, respectively) (Fig. 2 and Fig. 3).

Furthermore, there was a negative correlation between the frequencies of NK cells (CD3-/CD16+CD56+) and NKT-like cells (CD3+/CD16+CD56+) $(r=-0.232$, $p=0.013$ ) (Fig. 4).

Patients who underwent elective splenectomy presented a higher amount of NK cells (CD3-/CD16+CD56+) than those with post-traumatic spleen removal ( $p=0.035)$ (Fig. 5).

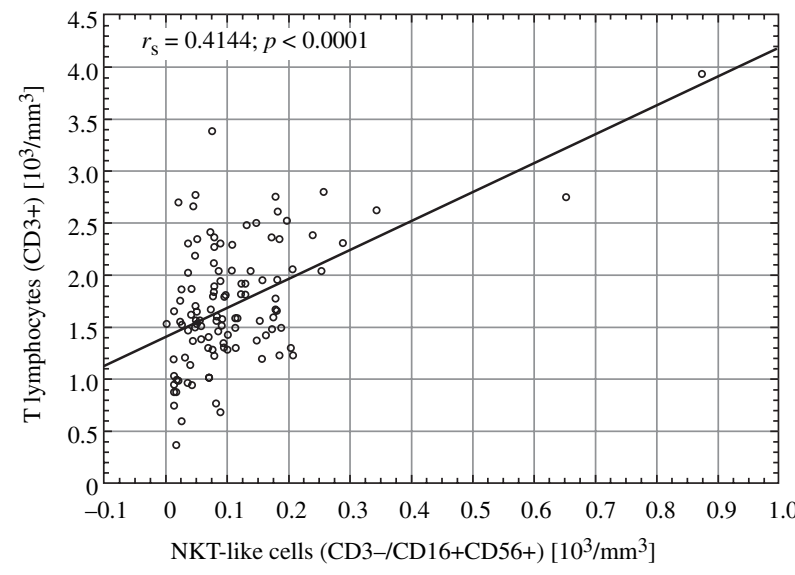

Fig. 3. Spearman correlation between total $\mathrm{T}$ lymphocytes count and NKT-like cells count $(r=0.414, p<0.0001)$

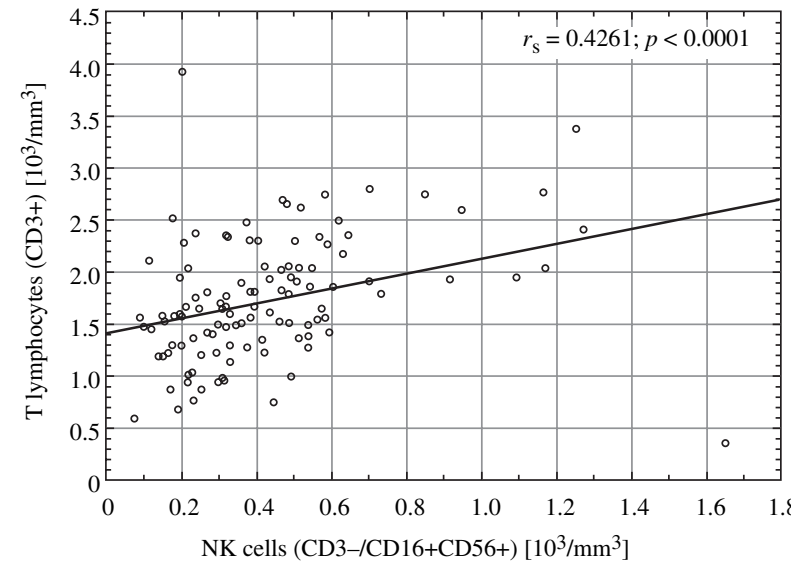

Fig. 2. Spearman correlation between total T lymphocytes count and NK cells count $(r=0.426, p<0.0001)$

The time since surgery negatively correlated with NK cells counts (CD3-/CD16+CD56+) (Fig. 6).

In those patients who noticed increased susceptibility to infections, the number of NK cells (CD3-/CD16+ CD56+) was lower $(p=0.007)$ than in those patients who did not observe any change in prevalence of infections (Fig. 7).

Moreover, those patients who noticed an increased infection rate had higher frequencies of NKT-like cells (CD3-/CD16+CD56+) comparing to those who did not observe any change in the prevalence of infections $(p=0.006)$ (Fig. 8).

\section{Discussion}

Acquired asplenia following splenectomy due to posttraumatic spleen rupture or as a treatment of certain hematologic diseases is a common abnormality. It is well estab-

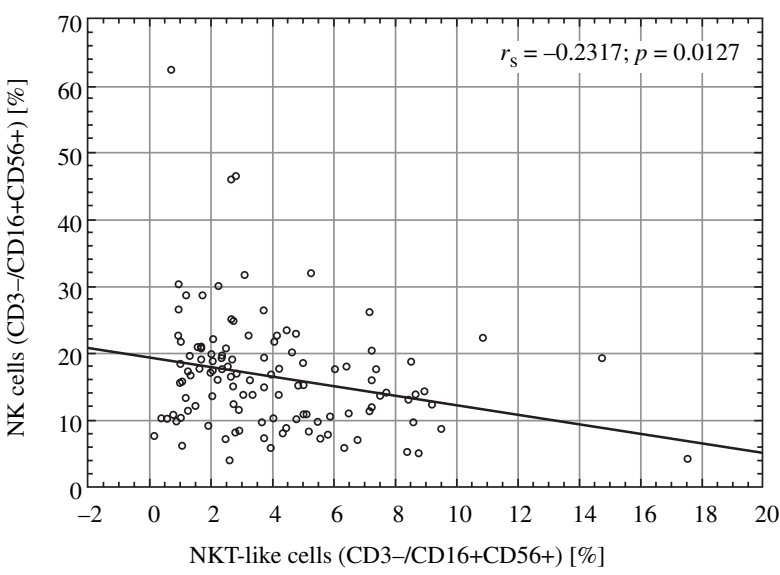

Fig. 4. Spearman correlation between the frequencies of NK cells (CD3-/CD16+CD56+) and NKT-like cells $(\mathrm{CD} 3+/ \mathrm{CD} 16+\mathrm{CD} 56+)(r=-0.232, p=0.013)$ 


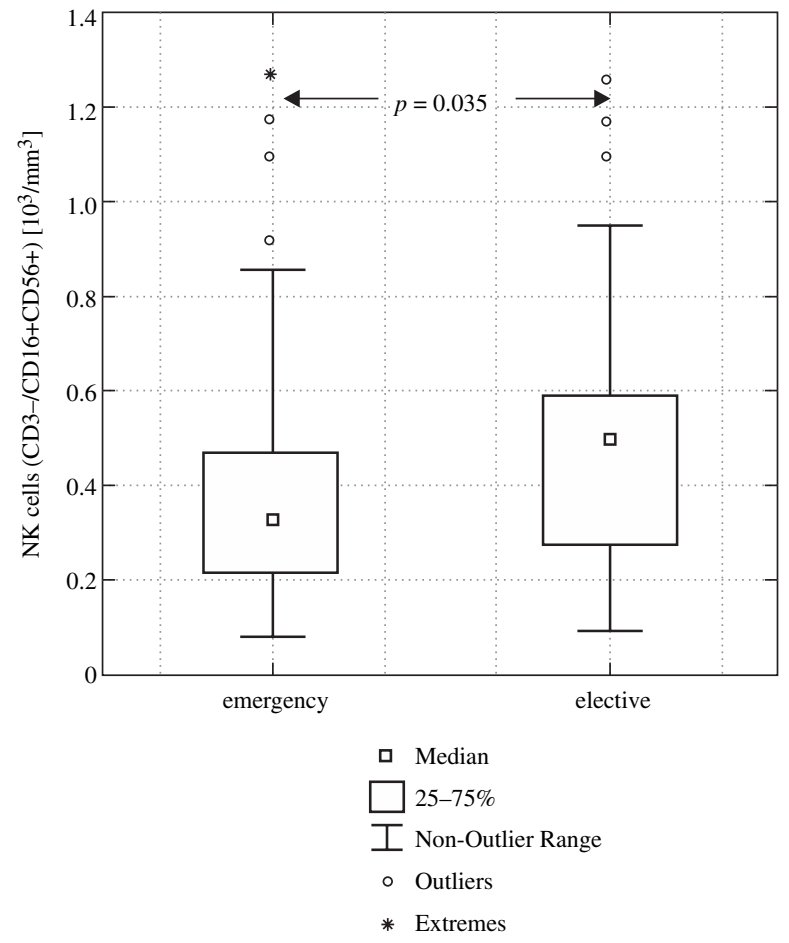

Fig. 5. Absolute counts of NK cells in the two groups of asplenic patients: those who underwent emergency splenectomy and those who underwent elective splenectomy $(p=0.035)$

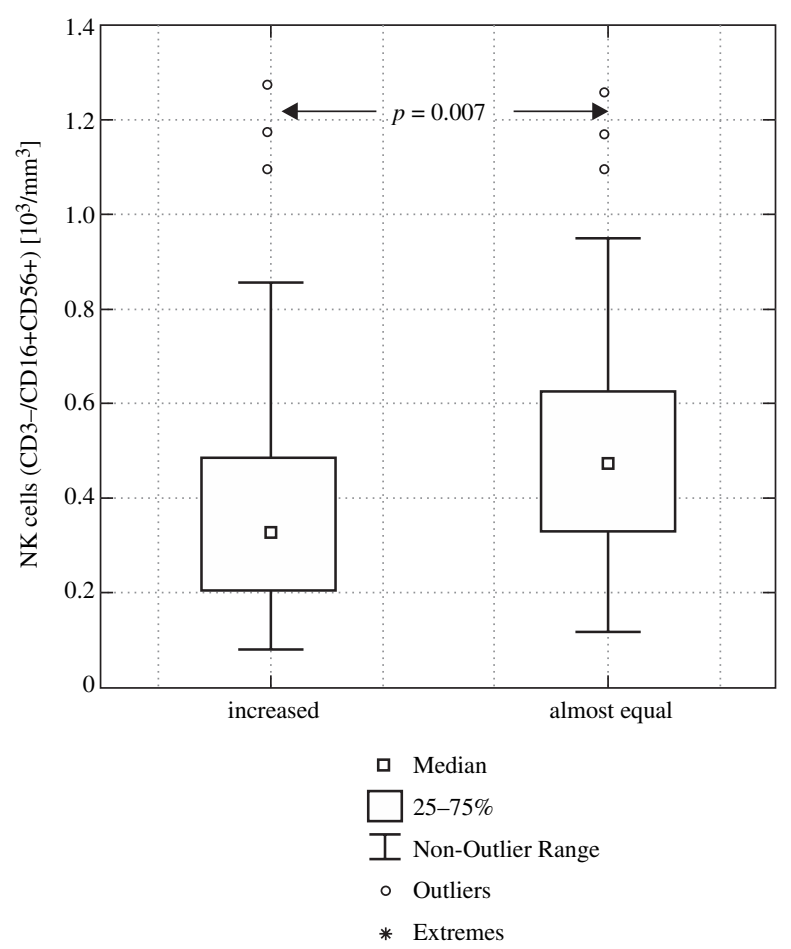

Fig. 7. Absolute counts of NK cells in the two groups of asplenic patients: those who noticed an increase in infections and those who did not observe any change in the prevalence of infections $(p=0.007)$

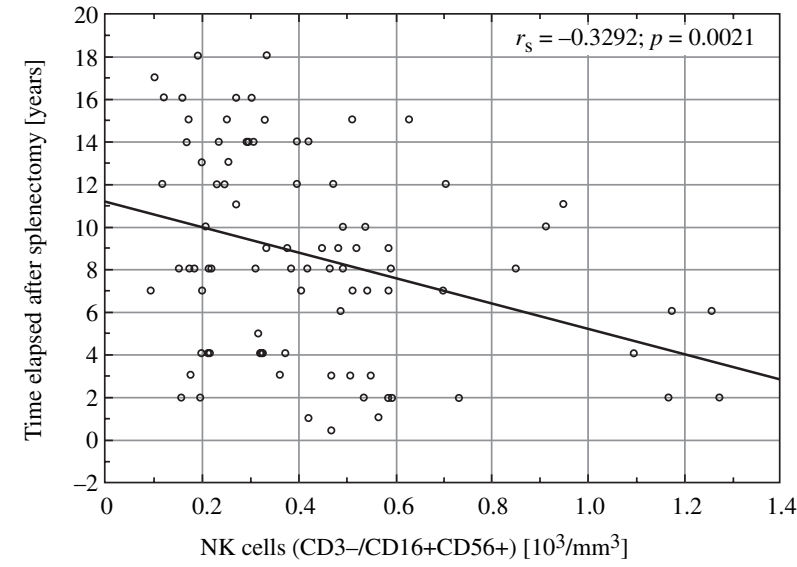

Fig. 6. A Spearman correlation between NK cells count and the time elapsed after splenectomy $(r=-0.329, p=-0.0021)$

lished that spleen removal has an influence on the total lymphocyte level as well as particular numbers of lymphocyte subsets [52-54]. According to our study, the total lymphocyte count and T lymphocyte subsets count after a splenectomy were insignificantly higher comparing to the control group whereas several other publications revealed a significant increase in total peripheral lymphocytes and T-lymphocytes in splenectomised patients $[55,56]$.

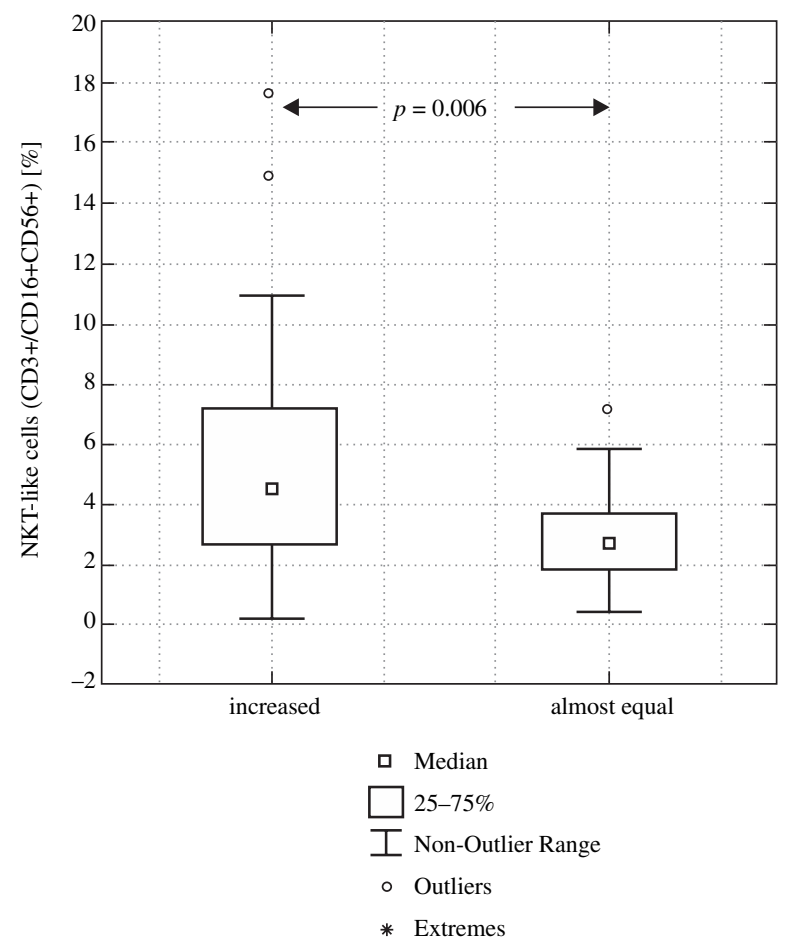

Fig. 8. Frequencies of NKT-like cells in the two groups of asplenic patients: those who noticed an increase in infections and those who did not observe any change in the prevalence of infections $(p=0.006)$ 
The lymphocytosis pattern may be different considering a reason of splenectomy. Post-traumatic splenectomy patients presented an increase in the absolute numbers of CD8+ and NK cells and, to a lesser extent, of NKT cells [57]. Asplenia due to autoimmune thrombocytopenic purpura (ATP) was connected only with persistent NK cell expansion [58]. Our data showed a higher amount of NK cells in patients who underwent elective splenectomy than those with posttraumatic spleen removal. However, in contrast to other authors, our results demonstrated a lower amount of NK cells and a higher amount of NKT-like cells than in the study group. Moreover, we observed that the ratio of NK and NKTlike cells was inversely proportional.

Several studies with a more detailed lymphocyte subsets analysis showed a substantial increase in the number of CD4+ and CD8+ lymphocytes but reduction in the CD4/CD8 ratio in splenectomised patients [52-54, 59, 60]. There is clinical evidence that a decrease in CD4+ T cells ratio was caused by a selective and long-term decrease in the percentage of CD4+CD45RA+ lymphocytes [61]. There is a difference between clinical studies and animal model research. In humans, post-splenectomy T cells subset redistribution lasted significantly longer [62, 63].

Our study revealed a relation between NK cells level and time elapsed after a splenectomy, while Winkelmeyer et al. did not notice any differences in immunological parameters in two groups that had undergone splenectomy 7 months to 5 years or 6 to 14 years earlier [64].

The mechanisms that play a fundamental role in bacterial clearance after a splenectomy are impaired, which results in an extended risk of infections. In accordance with that common observation, we noticed an increased frequency of infections following splenectomy. Natural killer T-like cells are important regulators of immunity against infectious diseases. They control bacterial clearance involving both innate and adaptive immunity [42]. On the other hand, they may be responsible for septic shock reaction through production of cytokines [50]. We described an elevated number of NKT-like cells in patients with a higher infection rate. Natural killer cells have a major role in defence against a broad spectrum of pathogens as well. A persistent increase in the absolute number and cytotoxic activity of NK cells which occurs after a splenectomy might probably compensate partially for the lack of phagocytic activity [65]. However, according to our findings, NK cells number in the study group was decreased, what was surprising, and related to a higher infection rate.

\section{Conclusions}

In conclusion, this research confirmed previous findings that total counts of lymphocytes and T lymphocyte subsets after a splenectomy were higher, but observed elevations were statistically insignificant. A lower post-splenec- tomy amount of NK cells is an unexpected result, considering other studies. An inversely proportional correlation between the ratio of NK and NKT-like cells was noticed. Increase in the infection rate corresponded with an elevated NKT-like cells number and a decreased NK cells count. In comparison to the preliminary research, this study provides a further piece of information on the complex immune disturbances in splenectomised individuals leading to the increased risk of bacterial infections. Results obtained suggest that monitoring of the NK and NKT-like cells number may provide useful information for determining aspleniarelated immunosuppression. Those outcomes require further investigation.

The authors declare no conflict of interests.

This study was supported by research grants No. 2011/01/N/NZ6/01762 and 2012/05/B/NZ6/00792 from National Science Centre, Poland.

\section{References}

1. Altamura M, Caradonna L, Amati L, et al. (2001): Splenectomy and sepsis: the role of the spleen in the immune-mediated bacterial clearance. Immunopharmacol Immunotoxicol 23: 153-161.

2. de Porto AP, Lammers AJ, Bennink RJ, et al. (2010): Assessment of splenic function. Eur J Clin Microbiol Infect Dis 29: 1465-1473.

3. Ram S, Lewis LA, Rice PA (2010): Infections of people with complement deficiencies and patients who have undergone splenectomy. Clin Microbiol Rev 23: 740-780.

4. Tiron A, Vasilescu C (2008): Role of the spleen in immunity. Immunologic consequences of splenectomy. Chirurgia (Bucur) 103: 255-263.

5. Lammers AJ, de Porto AP, Florquin S (2011): Enhanced vulnerability for Streptococcus pneumoniae sepsis during asplenia is determined by the bacterial capsule. Immunobiology 216 : 863-870.

6. Sims KD, Barton TD (2006): Group B streptococcal toxic shock syndrome in an asplenic patient: case report and literature review. Eur J Clin Microbiol Infect Dis 25: 208-210.

7. Holdsworth RJ, Irving AD, Cuschieri A (1991): Postsplenectomy sepsis and its mortality rate: actual versus perceived risks. Br J Surg 78: 1031-1038.

8. Jones P, Leder K, Woolley I, et al. (2010): Postsplenectomy infection - strategies for prevention in general practice. Aust Fam Physician 39: 383-386.

9. Caligiuri MA (2008): Human natural killer cells. Blood 112: 461-469.

10. Vivier E, Tomasello E, Baratin M, et al. (2008): Functions of natural killer cells. Nat Immunol 9: 503-510.

11. Cooper MA, Fehniger TA, Caligiuri MA (2001): The biology of human natural killer-cell subsets. Trends Immunol 22: 633-640.

12. Poli A, Michel T, Thérésine M, et al. (2008): CD56 bright natural killer (NK) cells: an important NK cell subset. Immunology $126: 458-465$. 
13. Cooper MA, Fehniger TA, Turner SC, et al. (2001): Human natural killer cells: a unique innate immunoregulatory role for the CD56 bright subset. Blood 97: 3146-3151.

14. Zucchini N, Crozat K, Baranek T, et al. (2008): Natural killer cells in immunodefense against infective agents. Expert Rev Anti Infect Ther 6: 867-885.

15. Vivier E, Raulet DH, Moretta A, et al. (2011): Innate or adaptive immunity? The example of natural killer cells. Science 331: 44-49.

16. Langers I, Renoux VM, Thiry M, et al. (2012): Natural killer cells: role in local tumor growth and metastasis. Biologics 6 : 73-82.

17. Paust S, Senman B, von Andrian UH (2010): Adaptive immune responses mediated by natural killer cells. Immunol Rev 235 : 286-296.

18. Cooper MA, Colonna M, Yokoyama WM (2009): Hidden talents of natural killers: NK cells in innate and adaptive immunity. EMBO Rep 10: 1103-1110.

19. Jewett A, Man YG, Tseng HC (2013): Dual functions of natural killer cells in selection and differentiation of stem cells; role in regulation of inflammation and regeneration of tissues. J Cancer 4: 12-24.

20. Clément MV, Haddad P, Soulié A, et al. (1990): Involvement of granzyme B and perforin gene expression in the lytic potential of human natural killer cells. Res Immunol 141: 477-489.

21. Takeda K, Hayakawa Y, Smyth MJ, et al. (2001): Involvement of tumor necrosis factor-related apoptosis-inducing ligand in surveillance of tumor metastasis by liver natural killer cells. Nat Med 7: 94-100.

22. Fang R, Ismail N, Walker DH (2012): Contribution of NK cells to the innate phase of host protection against an intracellular bacterium targeting systemic endothelium. Am J Pathol 181: 185-195.

23. Walzer T, Dalod M, Robbins SH, et al. (2005): Natural-killer cells and dendritic cells: "L'union fait la force". Blood 106: 2252-2258.

24. Costantini C, Micheletti A, Calzetti F, et al. (2010): Neutrophil activation and survival are modulated by interaction with NK cells. Int Immunol 22: 827-838.

25. Michel T, Hentges F, Zimmer J (2012): Consequences of the crosstalk between monocytes/macrophages and natural killer cells. Front Immunol 3: 403.

26. Cooper MA, Yokoyama WM (2010): Memory-like responses of natural killer cells. Immunol Rev 235: 297-305.

27. Strowig T, Brilot F, Münz C (2008): Noncytotoxic functions of NK cells: direct pathogen restriction and assistance to adaptive immunity. J Immunol 180: 7785-7791.

28. Bryceson YT, Long EO (2008): Line of attack: NK cell specificity and integration of signals. Curr Opin Immunol 20: 344-352.

29. Stephen KA (2005): Biology of natural killer cells: what is the relationship between natural killer cells and cancer? Will an increased number and/or function of natural killer cells result in lower cancer incidence? J Nutr 135: 2910S.

30. Orange JS (2006): Human natural killer cell deficiencies. Curr Opin Allergy Clin Immunol 6: 399-409.

31. Davodeau F, Peyrat MA, Necker A, et al. (1997): Close phenotypic and functional similarities between human and murine alphabeta T cells expressing invariant TCR alpha-chains. J Immunol 158: 5603-5611.

32. Laloux V, Beaudoin L, Ronet C, Lehuen A (2002): Phenotypic and functional differences between NKT cells colonizing splanchnic and peripheral lymph nodes. J Immunol 168: 3251-3258.

33. Lantz O, Bendelac A (1994): An invariant T cell receptor $\alpha$ chain is used by a unique subset of MHC class I-specific CD4+ and CD4-CD8- T cells in mice and humans. J Exp Med 180: 1097-1106.

34. Takahashi T, Nieda M, Koezuka Y, et al. (2000): Analysis of human V alpha 24+ CD4+ NKT cells activated by alpha-glycosylceramide-pulsed monocyte-derived dendritic cells. J Immunol 164: 4458-4464.

35. Van Der Vliet HJ, Nishi N, Koezuka Y, et al. (1999): Effects of alphagalactosylceramide (KRN7000), interleukin-12 and interleukin-7 on phenotype and cytokine profile of human Va24+ Vb11+ T cells. Immunology 4: 557-563.

36. Balato A, Unutmaz D, Gaspari AA (2009): Natural killer T cells: an unconventional T-cell subset with diverse effector and regulatory functions. J Invest Dermatol 129: 1628-1642.

37. Crowe NY, Coquet JM, Berzins SP, et al. (2005): Differential antitumor immunity mediated by NKT cell subsets in vivo. J Exp Med 202: 1279-1288.

38. Werner JM, Busl E, Farkas SA, et al. (2011): DX5+NKT cells display phenotypical and functional differences between spleen and liver as well as NK1.1-Balb/c and NK1.1+ C57B1/6 mice. BMC Immunol 12: 26.

39. Lawson V (2012): Turned on by danger: activation of CD1 d-restricted invariant natural killer T cells. Immunology 137: 20-27.

40. Cohen NR, Garg S, Brenner MB (2009): Antigen presentation by CD1 lipids, T cells, and NKT cells in microbial immunity. Adv Immunol 102: 1-94.

41. Terabe M, Swann J, Ambrosino E, et al. (2005): A nonclassical non-Valpha14Jalpha18 CD1d-restricted (type II) NKT cell is sufficient for down-regulation of tumor immunosurveillance. J Exp Med 202: 1627-1633.

42. Terabe M, Berzofsky JA (2008): The role of NKT cells in tumor immunity. Adv Cancer Res 2008; 101: 277-348.

43. Ken-ichiro S, Masaru T (2005): NKT cells: a regulator in both innate and acquired immunity. Curr Med Chem 4: 59-64.

44. Jiang X, Kojo S, Harada M, et al. (2007): Mechanism of NKT cell-mediated transplant tolerance. Am J Transplant 7: 1482-1490.

45. Meyer EH, DeKruyff RH, Umetsu DT (2007): iNKT cells in allergic disease. Curr Top Microbiol Immunol 314: 269-291.

46. Tarazona R, DelaRosa O, Peralbo E, et al. (2003): Human NKT cells in health and disease. Inmunologia 22: 359-370.

47. Godfrey DI, MacDonald HR, Kronenberg M, et al. (2004): NKT cells: what's in a name? Nat Rev Immunol 4: 231-237.

48. Kinjo Y, Wu D, Kim G, et al. (2005): Recognition of bacterial glycosphingolipids by natural killer $\mathrm{T}$ cells. Nature 434 : 520-525.

49. Brigl M, Tatituri RV, Watts GF, et al. (2011): Innate and cytokine-driven signals, rather than microbial antigens, dominate in natural killer $\mathrm{T}$ cell activation during microbial infection. J Exp Med 208: 1163-1177.

50. Mattner J, Debord KL, Ismail N, et al. (2005): Exogenous and endogenous glycolipid antigens activate NKT cells during microbial infections. Nature 434: 525-529.

51. Terabe M, Berzofsky JA (2007): NKT cells in immunoregulation of tumor immunity: a new immunoregulatory axis. Trends Immunol 28: 491-496.

52. Dürig M, Landmann RM, Harder F (1984): Lymphocyte subsets in human peripheral blood after splenectomy and autotransplantation of splenic tissue. J Lab Clin Med 104: 110-115. 
53. Brodsky E, Steiner Z, Manor Y, et al. (1988): Changes in lymphocyte subpopulations in peripheral blood of splenectomized patients. Isr J Med Sci 24: 702-705.

54. Ferrante A, Drew PA, Kiroff GK, Zola H. (1987): Peripheral blood leucocyte subpopulations in patients splenectomized for trauma. Clin Exp Immunol 70: 158-163.

55. Lauria F, Pulvirenti A, Raspadori D, Tura S (1981): T-lymphocyte subsets in healthy splenectomised patients. Boll Ist Sieroter Milan 60: 417-420.

56. Mazzucconi MG, Piola P, Arista MC, et al. (2000): Modifications of lymphocyte subsets in autoimmune thrombocytopenic purpura patients submitted to splenectomy. Haematologica 85: 776-777.

57. Theodorou GL, Mouzaki A, Tsiftsis D, et al. (2007): Effect of non-operative management (NOM) of splenic rupture versus splenectomy on the distribution of peripheral blood lymphocyte populations and cytokine production by T cells. Clin Exp Immunol 150: 429-436.

58. Garcia-Suarez J, Prieto A, Reyes E, et al. (1995): Persistent lymphocytosis of natural killer cells in autoimmune thrombocytopenic purpura (ATP) patients after splenectomy. $\mathrm{Br}$ J Haematol 89: 653-655.

59. Wang WC, Herrod HG, Valenski WR, Wyatt RJ (1988): Lymphocyte and complement abnormalities in splenectomized patients with hematologic disorders. Am J Hematol 28: 239-245.

60. Sieber G, Breyer HG, Herrmann F, Rühl H (1985): Abnormalities of B-cell activation and immunoregulation in splenectomized patients. Immunobiology 169: 263-271.

61. Wolf HM, Eibl MM, Georgi E, et al. (1999): Long-term decrease of CD4+CD45RA $+\mathrm{T}$ cells and impaired primary immune response after post-traumatic splenectomy. $\mathrm{Br}$ J Haematol 107: 55-68.

62. Karakantza M, Theodorou GL, Mouzaki A, et al. (2004): In vitro study of the long-term effects of post-traumatic splenectomy on cellular immunity. Scan J Immunol 59: 209-219.

63. Westermann J, Schwinzer R, Jecker P, Pabst R (1990): Lymphocyte subsets in the blood. The influence of splenectomy, splenic autotransplantation, ageing, and the site of blood sampling on the number of B, T, CD4+, and CD8+ lymphocytes in the rat. Scand J Immunol 31: 327-334.

64. Winkelmeyer M, Littmann K, Thraenhart O, et al. (1981): Alterations of humoral and cellular immunity after splenectomy. Klin Wochenschr 59: 485-493.

65. Ferrante A, Kiroff GK, Drew PA (1986): Elevated natural killer (NK) cytotoxicity of mononuclear leucocytes from splenectomized patients: increase in Leu-7+ and Leu- $11^{+}$leucocytes. Clin Exp Immunol 64: 173-180. 